\title{
Expression of Krüppel-like factor 4 in breast cancer tissues and its effects on the proliferation of breast cancer MDA-MB-231 cells
}

\author{
XIANG SONG, YUE-MING XING, WEI WU, GUO-HUA CHENG, \\ FENG XIAO, GANG JIN, YING LIU and XIN ZHAO
}

\author{
Department of Oncology, The Second Hospital of Shanxi Medical University, Taiyuan, Shanxi 030001, P.R. China
}

Received October 22, 2015; Accepted December 9, 2016

DOI: $10.3892 /$ etm.2017.4262

\begin{abstract}
The aim of the present study was to detect the expression of Krüppel-like factor 4 (KLF4) in breast cancer tissues and to evaluate the effect on the proliferation of breast cancer MDA-MB-231 cells. The expression of KLF4 protein in 239 breast cancer tissues and 40 paracancerous tissues were detected by an immunohistochemical assay, and its correlation with clinical pathological parameters was analyzed. A eukaryotic expression vector, pcDNA3.1-KLF4, was constructed by transient transfection of breast cancer MDA-MB-231 cells with liposomes (experimental group). The untransfected cells and those transfected with empty plasmid pcDNA3.1 were used as the blank and negative control groups, respectively. The expression of the KLF4 gene and protein in the three groups were detected by reverse transcription polymerase chain reaction and western blotting, respectively. Furthermore, the cell proliferative capacity was detected by an MTT assay. The positive expression rate of KLF4 protein in breast cancer tissues $(39.0 \%, 93 / 239)$ was significantly lower than that of paracancerous tissues $(77.5 \%, 31 / 40)(\mathrm{P}<0.05)$. In addition, KLF4 protein expression in breast cancer tissues was correlated with pathological type, histological grade and lymphatic metastasis $(\mathrm{P}<0.05)$. KLF4 mRNA and protein were both expressed by the experimental group, but not by the two control groups. Meanwhile, the proliferative capacity of the experimental group was also significantly decreased. A significant decrease in the positive expression rate of KLF4 protein in breast cancer tissues was correlated with several clinical pathological parameters. In addition, transfection of the KLF4 gene inhibited the proliferation of breast cancer cells, suggesting that this gene is important in the onset and progression of this type of cancer.
\end{abstract}

Correspondence to: Dr Xiang Song, Department of Oncology, The Second Hospital of Shanxi Medical University, 382 Wuyi Road, Taiyuan, Shanxi 030001, P.R. China

E-mail: songxiangdo@yeah.net

Key words: Krüppel-like factor 4, breast cancer, cell proliferation

\section{Introduction}

Breast cancer, as one of the most common malignant tumor types affecting women worldwide, severely threatens their physiological and psychological health (1). In 2008, almost 1.4 million women were diagnosed with breast cancer worldwide, and $\sim 459,000$ instances of breast cancer-associated mortality were recorded (2). In China, the incidence rate and mortality rate of breast cancer rank first and fifth, respectively, among all types of cancer (3). As with other types of cancer, breast cancer involves multiple genes and factors, including hormonal and reproductive factors such as progesterone and estrogen receptors (4). Therefore, it is important to determine appropriate markers in order to determine the molecular mechanism for its onset and progression. Krüppel-like factor 4 (KLF4), which is a member of the KLF family, is a transcription element-binding protein that is present across eukaryotes (5). Three continuous zinc finger domains at the C-terminus are bound to GC-rich sequences in the promoter region of the target gene, regulating the transcription of KLF4 (6). Besides being associated with the growth, differentiation and apoptosis of normal tissue cells, KLF4 may function as an oncogene in liver cancer or as a tumor suppressor in renal cell carcinoma by interacting with different target genes (7-9). The role of KLF4 in breast cancer remains controversial. Therefore, KLF4 gene expression was determined in tissue from patients with breast cancer and analyzed the correlation with clinical pathological parameters. In addition, an expression vector, pcDNA3.1-KLF4, was constructed and expressed by transient transfection into the breast cancer cell line MDA-MB-231, in order to observe the effects of the KLF4 gene in cell proliferation.

\section{Materials and methods}

Sample sources. A total of 239 cancerous tissue samples were collected from 239 patients with breast cancer who received radical mastectomy in The Second Hospital of Shanxi Medical University between January 2009 and October 2014 to prepare tissue microarrays that contained primary foci. In addition, 40 samples of paracancerous tissues were harvested from randomly selected patients in this group. Patients did not receive chemotherapy or radiotherapy prior to the surgery, and the results of postoperative pathological examination were confirmed by at least two pathologists. The clinical medical 
records were all complete. The present study was approved by the Ethics Committee of The Second Hospital of Shanxi Medical University (Taiyuan, China), and written consent was obtained from all patients.

Materials. The human breast cancer cell line MDA-MB-231 was purchased from the Cell Bank/Stem Cell Bank, Shanghai Institute for Biological Sciences, CAS (Shanghai, China). Rabbit anti-human KLF4 monoclonal antibody (cat. no. ab72543) was purchased from Abcam (Cambridge, UK). Streptavidin-peroxidase (SP) conjugate immunohistochemical assay kit (cat. no. SA-5004) was purchased from Vector Laboratories, Inc., (Burlingame, CA, USA) and the 3,3'-diaminobenzidine color development kit (cat. no. ab94665) was purchased from Abcam (Cambridge, UK). Lipofectamine ${ }^{\circledR} 2000$ (cat. no. 11668019), the western blot detecting chemiluminescent kit (cat. no. WB7106) and the bicinchoninic acid assay (BCA) protein determination kit (cat. no. 23225) were obtained from Thermo Fisher Scientific, Inc. (Waltham, MA, USA). TRIzol and the reverse transcription (RT) kit (PrimeScript RT reagent kit; cat. no. RR037A) were purchased from Takara Bio, Inc. (Otsu, Japan), and primers were synthesized by Sangon Biotech Co., Ltd. (Shanghai, China).

Detection of KLF4 protein expression by immunohistochemistry. All samples were stained using the SP method according to the manufacturer's protocol, and the primary antibody was replaced with PBS as a negative control. In total, 5 high-power fields were randomly selected for each sample, and the staining results were analyzed according to the percentages of positive cells and the staining intensities, as described previously (10). The positive cells were counted based on the proportions of their numbers to the total number in the 5 high-power fields, as follows: $<5 \%$, 0 point; $5-25 \%, 1$ point; $26-50 \%, 2$ points; $51-75 \%, 3$ points and $76-100 \%, 4$ points. The scoring based on staining intensities was as follows: pale yellow, 1 point; yellow or dark yellow, 2 points and brown or sepia, 3 points. In addition, the multiplication of the two results were considered to be positive if $\geq 1$ and negative if $<1$. Estrogen and progesterone receptors were also detected in cells using hematoxylin and eosin staining as described previously (11).

Culture of breast cancer cells. Proliferating MDA-MB-231 cells were cultured in Dulbecco's modified Eagle's medium (DMEM) containing $10 \%$ fetal bovine serum in a $37^{\circ} \mathrm{C}$ incubator with $5 \% \mathrm{CO}_{2}$ atmosphere and saturated humidity, and the cells were then passaged. Cells in the logarithmic growth phase were selected for subsequent experiments.

Cell transfection and grouping. Eukaryotic expression vector pcDNA3.1-KLF4 was constructed by Tiandz Gene Technology Co., Ltd. (Beijing, China). An MDA-MB-231 single-cell suspension $\left(1 \times 10^{4}\right.$ cells $\left./ \mathrm{ml}\right)$ was inoculated onto 6-well plates and cultured for $24 \mathrm{~h}$ at $37^{\circ} \mathrm{C}$ in an atmosphere containing $5 \% \mathrm{CO}_{2}$ after addition of DMEM containing $10 \%$ fetal bovine serum. The cells were divided into three groups: An experimental group (transfected with pcDNA3.1-KLF4 plasmid), a negative control group (transfected with empty plasmid pcDNA3.1) and a blank control group (untransfected cells). The cells were transfected according to the protocol of the Lipofectamine ${ }^{\circledR} 2000$ kit. After 8 h of transfection, DMEM containing $10 \%$ fetal bovine serum was replaced to culture the cells for another $48 \mathrm{~h}$.

Detection of KLF4 mRNA expression by RT-polymerase chain reaction $(P C R)$. Cells were collected after $48 \mathrm{~h}$ of transfection, from which total mRNA was extracted using TRIzol. A total of $100 \mathrm{ng}$ cDNA was synthesized from $1 \mu \mathrm{g}$ total mRNA. mRNA was denatured at $65^{\circ} \mathrm{C}$ for $5 \mathrm{~min}$ and RT was performed with the PrimeScript RT reagent kit at $50^{\circ} \mathrm{C}$ for $50 \mathrm{~min}$. The reaction was stopped by denaturing the enzyme at $70^{\circ} \mathrm{C}$ for 50 min and cDNA was stored at $-20^{\circ} \mathrm{C}$. PCR was performed at $95^{\circ} \mathrm{C}$ for $30 \mathrm{sec}, 95^{\circ} \mathrm{C}$ for $3 \mathrm{sec}$ and $60^{\circ} \mathrm{C}$ for $30 \mathrm{sec}$, for 40 cycles. Primers were annealed at $62^{\circ} \mathrm{C}$ for $40 \mathrm{sec}$. The PCR reaction mixture contained the following: cDNA, $1 \mu 1$; reverse primer, $1 \mu \mathrm{l}$; forward primer; $1 \mu \mathrm{l}$; dNTPs, $1 \mu \mathrm{l}$; MasterMix, $10 \mu \mathrm{l}$; DMSO, $1 \mu \mathrm{l}$; and water, $5 \mu \mathrm{l}$. GAPDH was used as the internal reference. The PCR reagent kit (cat. no. RR036Q) was purchased from Takara Bio, Inc. (CA, USA).

This experiment was performed in triplicate for each sample. Following the reaction, the products were resolved on a $1.5 \%$ agarose gel by electrophoresis. The sequences of the KLF4 primer were as follows: forward, 5'-ACCAGGCAC TACCGTAAACACA-3' and reverse, 5'-GGTCCGACCTGG AAAATGCT-3'. In addition, the sequences of the GAPDH primer were: forward, 5'-GAAGGTGAAGGTCGAAGT-3' and reverse, 5'-GAAGATGGTGATGGGATTT-3'.

Detection of KLF4 protein expression by western blotting. After $48 \mathrm{~h}$ of transfection, the cells were collected in order to extract the total protein, the concentration of which was determined by the BCA method. The protein samples were loaded, separated by $10 \%$ SDS-PAGE, and transferred to a nitrocellulose membrane at $250 \mathrm{~mA}$ for $90 \mathrm{~min}$. These membranes were blocked in 5\% skimmed milk for $1 \mathrm{~h}$ and incubated overnight with a primary antibody against KLF4 $(1: 1,000)$ at $4^{\circ} \mathrm{C}$. After this, the membrane was washed three times with Tris-buffered saline and Tween-20 (TBST) (10 min each time), incubated with TBST-diluted horseradish peroxidase (HRP)-labeled secondary antibody $(1: 6,000)$ at room temperature for $1 \mathrm{~h}$ and washed three more times with TBST (5 min each time). Subsequently, the membranes were incubated with Luminata Forte Western HRP Substrate (EMD Millipore, Billercia, MA, USA) for 3 min or Western Bright (Advansta) in 1:1 dilution with water for $30 \mathrm{sec}$. Under red safelight, the membranes were evaluated with an X-ray Film (Super RX; Fujifilm, Tokyo, Japan) on an X-ray developing unit (Agfa-Gevaert, Mortsel, Belgium) for $10 \mathrm{~min}$. $\beta$-actin was used as an internal reference, with an antibody purchased from Santa Cruz Biotechnology, Inc. (Dallas, TX, USA; 1:1,500; cat. no. ab8227).

Detection of cell proliferation by the MTT assay. Following $48 \mathrm{~h}$ of transfection the cells were collected and prepared into a single-cell suspension that was inoculated onto 96-well plates at a density of $1 \times 10^{4}$ cells/well. The experiment was performed in triplicate for each sample. The cells were thereafter cultured in a $37^{\circ} \mathrm{C}$ incubator with a $5 \% \mathrm{CO}_{2}$ atmosphere and saturated humidity, and $10 \mu \mathrm{l}$ of $5 \mathrm{mg} / \mathrm{ml}$ MTT was added 24, 48 and $72 \mathrm{~h}$ later. After another $4 \mathrm{~h}$ of culture, the supernatant was removed, and $150 \mu 1$ of dimethyl sulfoxide was added in each well. Next, the plates were oscillated for $10 \mathrm{~min}$. The optical 
Table I. Correlation between positive KLF4 protein expression and clinical pathological parameters.

\begin{tabular}{|c|c|c|c|c|c|}
\hline $\begin{array}{l}\text { Clinical pathological } \\
\text { parameter }\end{array}$ & Subcategories & $\begin{array}{c}\text { Total } \\
\text { samples }\end{array}$ & $\begin{array}{l}\text { Positive KLF4 } \\
\text { expression, n (\%) }\end{array}$ & $\chi^{2}$ value & P-value \\
\hline Age, years & $\begin{array}{l}\leq 51 \\
>51\end{array}$ & $\begin{array}{l}133 \\
106\end{array}$ & $\begin{array}{l}58(43.6) \\
35(33.0)\end{array}$ & 2.944 & 0.086 \\
\hline Tumor size, $\mathrm{cm}$ & $\begin{array}{l}\leq 2 \\
2-5 \\
>5\end{array}$ & $\begin{array}{r}71 \\
109 \\
59\end{array}$ & $\begin{array}{l}26(36.6) \\
45(41.3) \\
22(37.3)\end{array}$ & 1.290 & 0.525 \\
\hline Tumor type & $\begin{array}{l}\text { Early invasive carcinoma } \\
\text { Infiltrating ductal carcinoma } \\
\text { Invasive carcinoma of } \\
\text { no special type }\end{array}$ & $\begin{array}{r}21 \\
49 \\
169\end{array}$ & $\begin{array}{l}10(47.6) \\
26(53.1) \\
57(33.7)\end{array}$ & 6.539 & 0.039 \\
\hline Histological grade & $\begin{array}{l}\text { I } \\
\text { II } \\
\text { III }\end{array}$ & $\begin{array}{r}32 \\
142 \\
65\end{array}$ & $\begin{array}{l}16(50.0) \\
60(42.3) \\
17(26.2)\end{array}$ & 7.210 & 0.026 \\
\hline Lymphatic metastasis & $\begin{array}{l}\text { No } \\
\text { Yes }\end{array}$ & $\begin{array}{r}143 \\
96\end{array}$ & $\begin{array}{l}64(44.8) \\
29(30.2)\end{array}$ & 5.315 & 0.019 \\
\hline Estrogen receptor & $\begin{array}{l}\text { Negative } \\
\text { Positive }\end{array}$ & $\begin{array}{l}127 \\
112\end{array}$ & $\begin{array}{l}50(39.4) \\
43(38.4)\end{array}$ & 0.042 & 0.837 \\
\hline Progesterone receptor & $\begin{array}{l}\text { Negative } \\
\text { Positive }\end{array}$ & $\begin{array}{l}137 \\
102\end{array}$ & $\begin{array}{l}55(40.1) \\
38(37.3)\end{array}$ & 0.155 & 0.695 \\
\hline
\end{tabular}
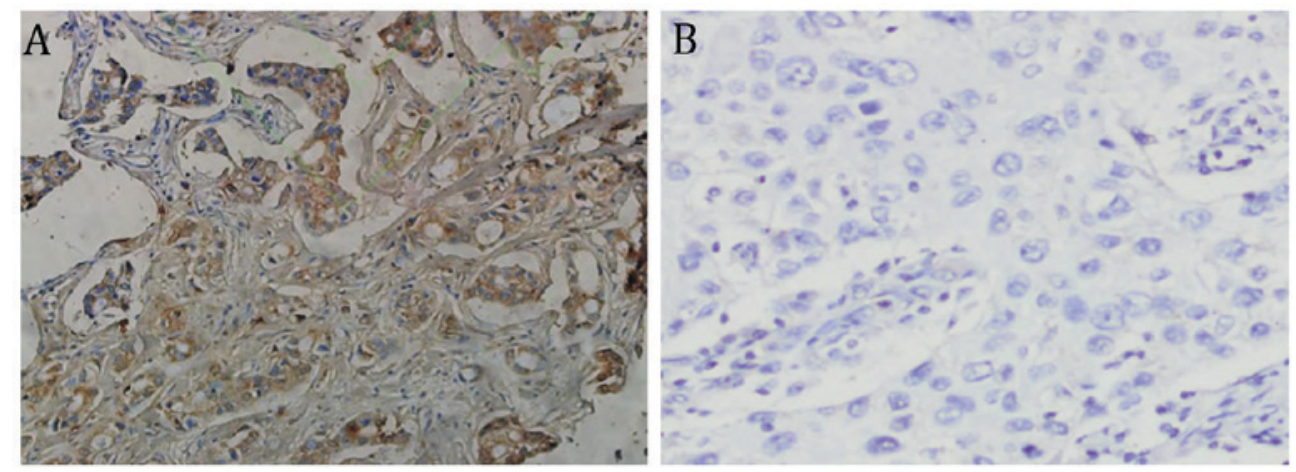

Figure 1. Krüppel-like factor 4 protein expression in (A) paracancerous tissue; (B) breast cancer tissue. Magnification, $\mathrm{x} 400$.

density (OD) of each well was measured by a microplate reader (Biotek China, Beijing, China) at $492 \mathrm{~nm}$ and cell growth curves were plotted, using time as the $\mathrm{x}$-axis and the mean of $\mathrm{OD}$ values from three wells as the $\mathrm{y}$-axis.

Statistical analysis. All data were analyzed using SPSS 18.0 (SPSS, Inc., Chicago, IL, USA). The numerical data were compared by the $\chi^{2}$ test. For the categorical data, intergroup comparisons were performed by univariate analysis of variance, and further comparisons were conducted using Student's t-test or Fisher's Least Significant Difference test. $\mathrm{P}<0.05$ was considered to represent a statistically significant difference.

\section{Results}

KLF4 protein expression in breast cancer and paracancerous tissues. The tissues in which KLF4 protein was positively expressed were stained pale yellow to sepia. As shown in Fig. 1, the KLF4 protein expression assessment was predominantly negative in the majority of breast cancer tissues and positive in most paracancerous tissues. In addition, the positive expression rates were 39.0 (93/239 tissue samples) and $77.5 \%$ (31/40 tissue samples), respectively, which represented a significant difference $\left(\chi^{2}=20.462, P<0.05\right)$.

Correlation between KLF4 protein expression and clinical pathological parameters. Positive expression of the KLF4 protein was significantly associated with pathological type, histological grade and lymphatic metastasis $(\mathrm{P}<0.05)$ but was not significantly associated with age, tumor size, estrogen and progesterone receptor presence $(\mathrm{P}>0.05)$ (Table I).

Effects of KLF4 gene expression on the proliferation of MDA-MB-231 cells. KLF4 mRNA and protein expression, 

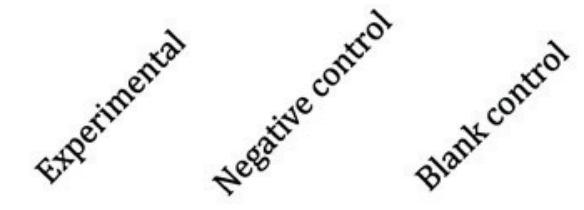

KLF4

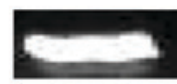

GAPDH

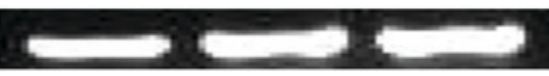

Figure 2. Krüppel-like factor 4 mRNA expression.

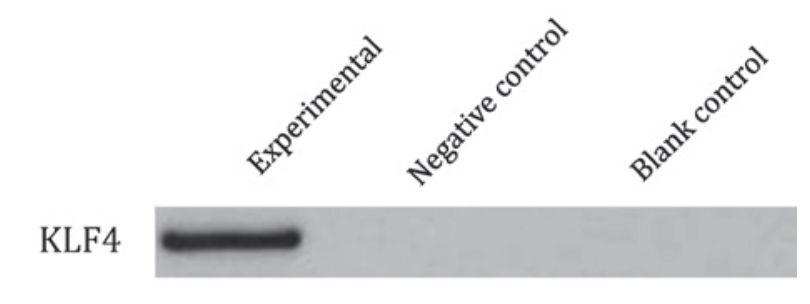

$\beta$-actin

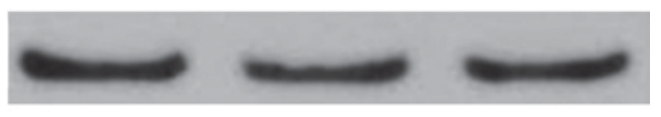

Figure 3. Krüppel-like factor 4 protein expression.

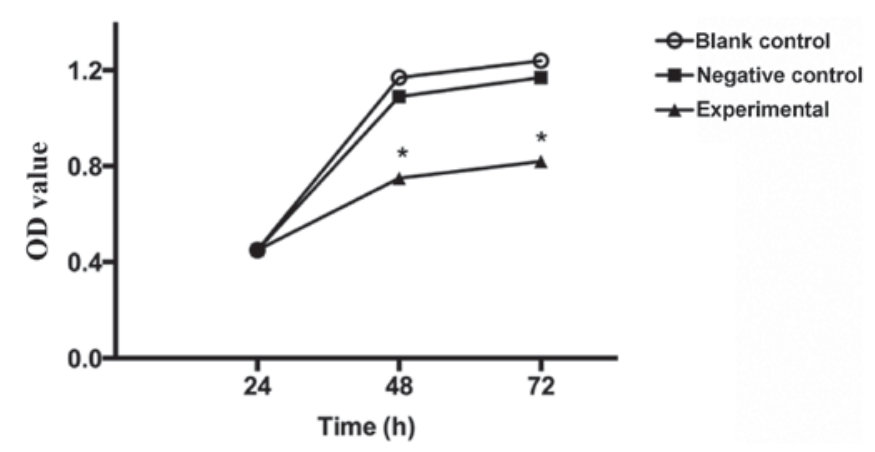

Figure 4. Cell growth curves. ${ }^{*} \mathrm{P}<0.05$ vs. negative and blank control groups at the same time points.

as indicated by RT-PCR (Fig. 2) and western blotting (Fig. 3), were expressed in the experimental group but not in the negative control or the blank control groups. The MTT assay revealed that after $24 \mathrm{~h}$ of culture, the experimental group grew similarly to the negative and blank control groups $(\mathrm{P}>0.05)$. After 48 and $72 \mathrm{~h}$ of culture, however, the growth of the experimental group significantly decreased compared with both groups $(\mathrm{P}<0.05)$, but growth of the other two groups did not differ significantly from each other $(\mathrm{P}>0.05)$ (Fig. 4). Therefore, overexpression of the KLF4 gene was able to inhibit the growth of breast cancer cells.

\section{Discussion}

The human KLF4 gene, which is 5,631 bp long and is located on chromosome 9q31, has five exons. The KLF4 mRNA is larger than this by $\sim 3.5 \mathrm{~kb}$, and its sequence contains 1,876 nucleotides (12). In addition, the KLF4 protein, which weighs $54,671 \mathrm{Da}$ and comprises 513 amino acid residues, contains three $\mathrm{C} 2 \mathrm{H} 2$ zinc-finger motifs (13). By directly activating or inhibiting the transcription of downstream genes, KLF4 is involved in cell cycle regulation, apoptosis, metabolism and stem cell self-renewal. As a regulatory factor for cell proliferation, KLF4 both induces and inhibits tumor formation. KLF4 is expressed at a low level in many types of human malignant tumors accompanied by hypermethylation and loss of heterozygosity $(14,15)$ and has inhibitory effects on gastric (16), colorectal (17), bladder (18) and lung (19) cancer. However, it is highly expressed in ductal carcinoma in situ and in oral squamous cell carcinoma compared with those in normal tissues $(20,21)$. For example, KLF4 overexpression leads to squamous cell carcinoma by inducing hyperplasia and dysplasia (22). Wei et al (23) identified that the expression of KLF4 mRNA and protein were upregulated in metastatic pancreatic and human pancreatic cancer tissues. Thus, differences in the expression of the KLF4 gene in various tumors may be associated with tissue specificity.

In the present study, low levels of the KLF4 protein were expressed in breast cancer tissues $(39.0 \%, 93 / 239)$ but high levels were expressed in paracancerous tissues $(77.5 \%, 31 / 40)$. The KLF4 protein expression in breast cancer tissues was negatively correlated with histological grade and lymphatic metastasis. Furthermore, the expression rates of KLF4 protein in early invasive carcinoma and infiltrating ductal carcinomas invasive carcinoma of special type were significantly higher than those in other types of carcinoma, which accounts for $\sim 80 \%$ of all breast cancer cases, with low degree of differentiation and poor prognosis (24). Hence, the KLF4 gene was negatively correlated with malignant behaviors of breast cancer, implying that this gene participated in several intracellular events and markedly suppressed the onset and progression of this type of cancer.

In order to clarify the role of the KLF4 gene in breast cancer, MDA-MB-231 cells were transiently transfected with a constructed eukaryotic expression vector called pcDNA3.1-KLF4. Western blotting demonstrated that the KLF4 protein, similar to KLF4 mRNA, was only expressed in the experimental group, suggesting that transcription of this gene enhanced target gene transcription in addition to protein translation. Additionally, the MTT assay demonstrated that the growth of the experimental group was significantly inhibited, indicating that KLF4 gene expression suppressed the proliferation of breast cancer cells. Given that the two control groups had similar outcomes, the vector did not affect cell proliferative capacity per se. Similarly to the inhibitory effects of the KLF4 gene on breast cancer progression, Yori et al (15) revealed that KLF4 overexpression in human breast cancer MDA-MB-231 cells upregulated the protein and mRNA levels of E-cadherin, which were decreased by interfering with its expression. Yori et al (25) also reported that KLF4 inhibited the invasion and distal metastasis of breast cancer by suppressing epithelial-mesenchymal transition.

Regardless, the influence of KLF4 on breast cancer remains controversial. Foster et al (22) demonstrated that KLF4 expression was increased in 6 out of 8 breast cancer cell lines, and in $70 \%$ of breast cancer tissue samples. Meanwhile, KLF4 was similarly expressed in ductal carcinoma in situ and invasive carcinoma, indicating that it may be associated with the early onset of breast cancer. Furthermore, KLF4 can 
maintain a high glycolytic metabolism through transcriptional activation of human platelet phosphofructokinase, thereby predominantly controlling the proliferation of breast cancer cells (26). It is likely that KLF4 also functions as an oncogene; whether KLF4 is an oncogene or a tumor suppressor may depend on the histological type and microenvironment. Serum starvation (27), oxidative stress (28) and interferon- $\gamma$ (29) may induce the production of KLF4, the expression of which can be downregulated by the hypermethylation and loss of heterozygosity in the promoter region (30). Accordingly, the role of KLF4 requires additional in-depth studies.

In summary, the positive expression rates of the KLF4 protein in breast cancer tissues significantly decreased, and transfection of the KLF4 gene significantly inhibited the proliferation of breast cancer cells, revealing that the KLF4 gene was crucial in the onset and progression of this type of cancer. The observations herein may allow the KLF4 gene to act as a novel target for the molecular diagnosis and gene therapy used to treat breast cancer.

\section{References}

1. Zeng H, Zheng R, Zhang S, Zou X and Chen W: Female breast cancer statistics of 2010 in China: Estimates based on data from 145 population-based cancer registries. J Thorac Dis 6: 466-470, 2014.

2. Youlden DR, Cramb SM, Dunn NA, Muller JM, Pyke CM and Baade PD: The descriptive epidemiology of female breast cancer: An international comparison of screening, incidence, survival and mortality. Cancer Epidemiol 36: 237-248, 2012.

3. Chen WQ, Zheng RS, Zhang SW, Li N, Zhao P, Li GL, Wu LY and He J: Report of incidence and mortality in china cancer registries, 2008. Chin J Cancer Res 24: 171-180, 2012.

4. Galvão ER, Martins LM, Ibiapina JO, Andrade HM and Monte SJ: Breast cancer proteomics: A review for clinicians. J Cancer Res Clin Oncol 137: 915-925, 2011.

5. Xue YK, Tan J, Dou DW, Chen D, Chen LJ, Ren HP, Chen LB, Xiong XG and Zheng H: Effect of Kruppel-like factor 4 on Notch pathway in hepatic stellate cells. J Huazhong Univ Sci Technolog Med Sci 36: 811-816, 2016.

6. Mahatan CS, Kaestner KH, Geiman DE and Yang VW: Characterization of the structure and regulation of the murine gene encoding gut-enriched Krüppel-like factor (Krüppel-like factor 4). Nucleic Acids Res 27: 4562-4569, 1999.

7. Rowland BD and Peeper DS: KLF4, p21 and context-dependent opposing forces in cancer. Nat Rev Cancer 6: 11-23, 2006.

8. Lin ZS, Chu HC, Yen YC, Lewis BC and Chen YW: Correction: Krüppel-like factor 4, a tumor suppressor in hepatocellular carcinoma cells reverts epithelial mesenchymal transition by suppressing slug expression. PLoS One 11: e0154168, 2016.

9. Li H, Wang J, Xiao W, Xia D, Lang B, Yu G, Guo X, Guan W, Wang Z, Hu Z, et al: Epigenetic alterations of Krüppel-like factor 4 and its tumor suppressor function in renal cell carcinoma. Carcinogenesis 34: 2262-2270, 2013.

10. Cao F, Wang K, Zhu R, Hu YW, Fang WZ and Ding HZ: Clinicopathological significance of reduced SPARCL1 expression in human breast cancer. Asian Pac J Cancer Prev 14: 195-200, 2013.

11. Bauer KR, Brown M, Cress RD, Parise CA and Caggiano V: Descriptive analysis of estrogen receptor (ER)-negative, progesterone receptor (PR)-negative, and HER2-negative invasive breast cancer, the so-called triple-negative phenotype: A population-based study from the California cancer registry. Cancer 109 $1721-1728,2007$

12. Evans PM and Liu C: Roles of Krüpel-like factor 4 in normal homeostasis, cancer and stem cells. Acta Biochim Biophys Sin (Shanghai) 40: 554-564, 2008.
13. Yet SF, McA'Nulty MM, Folta SC, Yen HW, Yoshizumi M, Hsieh CM, Layne MD, Chin MT, Wang H, Perrella MA, et al: Human EZF, a Krüppel-like zinc finger protein, is expressed in vascular endothelial cells and contains transcriptional activation and repression domains. J Biol Chem 273: 1026-1031, 1998.

14. Yoon HS, Chen X and Yang VW: Kruppel-like factor 4 mediates p53-dependent G1/S cell cycle arrest in response to DNA damage. J Biol Chem 278: 2101-2105, 2003.

15. Yori JL, Johnson E, Zhou G, Jain MK and Keri RA: Kruppel-like factor 4 inhibits epithelial-to-mesenchymal transition through regulation of E-cadherin gene expression. J Biol Chem 285: 16854-16863, 2010.

16. Wei D, Gong W, Kanai M, Schlunk C, Wang L, Yao JC, Wu TT, Huang S and Xie K: Drastic down-regulation of Krüppel-like factor 4 expression is critical in human gastric cancer development and progression. Cancer Res 65: 2746-2754, 2005.

17. Choi BJ, Cho YG, Song JW, Kim CJ, Kim SY, Nam SW, Yoo NJ, Lee JY and Park WS: Altered expression of the KLF4 in colorectal cancers. Pathol Res Pract 202: 585-589, 2006.

18. Ohnishi S, Ohnami S, Laub F, Aoki K, Suzuki K, Kanai Y, Haga K, Asaka M, Ramirez F and Yoshida T: Downregulation and growth inhibitory effect of epithelial-type Krüppel-like transcription factor KLF4, but not KLF5, in bladder cancer. Biochem Biophys Res Commun 308: 251-256, 2003.

19. Hu W, Hofstetter WL, Li H, Zhou Y, He Y, Pataer A, Wang L, Xie K, Swisher SG and Fang B: Putative tumor-suppressive function of Kruppel-like factor 4 in primary lung carcinoma. Clin Cancer Res 15: 5688-5695, 2009.

20. Chen YJ, Wu CY, Chang CC, Ma CJ, Li MC and Chen CM: Nuclear Krüppel-like factor 4 expression is associated with human skin squamous cell carcinoma progression and metastasis. Cancer Biol Ther 7: 777-782, 2008.

21. Tai SK, Yang MH, Chang SY, Chang YC, Li WY, Tsai TL, Wang YF, Chu PY and Hsieh SL: Persistent Krüppel-like factor 4 expression predicts progression and poor prognosis of head and neck squamous cell carcinoma. Cancer Sci 102: 895-902, 2011.

22. Foster KW, Liu Z, Nail CD, Li X, Fitzgerald TJ, Bailey SK, Frost AR, Louro ID, Townes TM, Paterson AJ, et al: Induction of KLF4 in basal keratinocytes blocks the proliferation-differentiation switch and initiates squamous epithelial dysplasia. Oncogene 24: 1491-1500, 2005.

23. Wei D, Wang L, Kanai M, Jia Z, Le X, Li Q, Wang H and Xie K: KLF4 $\alpha$ up-regulation promotes cell cycle progression and reduces survival time of patients with pancreatic cancer. Gastroenterology 139: 2135-2145, 2010.

24. Rakha EA, Reis-Filho JS, Baehner F, Dabbs DJ, Decker T, Eusebi V, Fox SB, Ichihara S, Jacquemier J, Lakhani SR, et al: Breast cancer prognostic classification in the molecular era: The role of histological grade. Breast Cancer Res 12: 207, 2010.

25. Yori JL, Seachrist DD, Johnson E, Lozada KL, Abdul-Karim FW, Chodosh LA, Schiemann WP and Keri RA: Krüppel-like factor 4 inhibits tumorigenic progression and metastasis in a mouse model of breast cancer. Neoplasia 13: 601-610, 2011.

26. Moon JS, Kim HE, Koh E, Park SH, Jin WJ, Park BW, Park SW and Kim KS: Krüppel-like factor 4 (KLF4) activates the transcription of the gene for the platelet isoform of phosphofructokinase (PFKP) in breast cancer. J Biol Chem 286: 23808-23816, 2011.

27. Chen ZY, Wang X, Zhou Y, Offner G and Tseng CC: Destabilization of Krüppel-like factor 4 protein in response to serum stimulation involves the ubiquitin-proteasome pathway. Cancer Res 65: 10394-10400, 2005.

28. Cullingford TE, Butler MJ, Marshall AK, Tham el L, Sugden PH and Clerk A: Differential regulation of Krüppel-like factor family transcription factor expression in neonatal rat cardiac myocytes: Effects of endothelin-1, oxidative stress and cytokines. Biochim Biophys Acta 1783: 1229-1236, 2008.

29. Chen ZY, Shie J and Tseng C: Up-regulation of gut-enriched krüppel-like factor by interferon-gamma in human colon carcinoma cells. FEBS Lett 477: 67-72, 2000.

30. Wei D, Kanai M, Huang S and Xie K: Emerging role of KLF4 in human gastrointestinal cancer. Carcinogenesis 27: 23-31, 2006. 